\title{
Secular Trends in Incidence and Mortality of Cervical Cancer in India and its States, 1990- 2019: Data from the Global Burden of Disease 2019 Study
}

\section{Mayank Singh}

International Institute for Population Sciences

Ravi Prakash Jha

Dr. Baba Saheb Ambedkar Medical College \& Hospital

Neha Shri

International Institute for Population Sciences

Krittika Bhattacharyya

University of Calcutta

Priyanka Patel

International Institute for Population Sciences

Deepak Dhamnetiya ( $\nabla$ drdeepakdhamnetiya@gmail.com )

Dr. Baba Saheb Ambedkar Medical College \& Hospital

\section{Research Article}

Keywords: cervical cancer, incidence, mortality, trend, joinpoint regression analysis, India, GBD

Posted Date: August 4th, 2021

DOl: https://doi.org/10.21203/rs.3.rs-696674/v1

License: (1) This work is licensed under a Creative Commons Attribution 4.0 International License.

Read Full License

Version of Record: A version of this preprint was published at BMC Cancer on February 7th, 2022. See the published version at https://doi.org/10.1186/s12885-022-09232-w. 


\section{Abstract}

Background: Cervical cancer is the fourth most common cancer that occurs to women worldwide. This study aims to assess trends in incidence and mortality of cervical cancer in India and its states over past three decades for tracking the progress of strategies for the prevention and control of cervical cancer.

Methods: Data on cervical cancer incidence and mortality from 1990 to 2019 for India and its states were extracted from Global Burden of Disease study and were utilized for the analysis. Spatial and rank map has been used to see the changes in incidence and mortality of cervical cancer in different Indian states. Further, joinpoint regression analysis is applied to determine the magnitude of the time trends in the age standardized incidence and mortality rates of cervical cancer. We obtained the average annual percent change (AAPC) and corresponding 95\% confidence intervals (CI) for each state.

Results: Overall, from 1990 to 2019 Jharkhand (Incidence: -50.22\%; Mortality: -56.16\%) recorded the highest percentage decrement in cervical cancer incidence and mortality followed by the Himachal Pradesh (Incidence: -48.34\%; Mortality: -53.37\%). Tamilnadu ( ${ }^{\text {st }}$ rank), Jammu \& Kashmir and Ladakh $\left(32^{\text {nd }}\right.$ rank) maintained the same rank over the period of three decade for age standardized cervical cancer incidence and mortality. The regression model showed a significant declining trend in India between 1990 and 2019 for age standardized incidence rate (AAPC: $-0.82 ; 95 \% \mathrm{Cl}:-1.39$ to $-0.25 ; \mathrm{p}<$ 0.05 ) with highest decline in the period $1998-2005$ (AAPC: $-3.22 ; 95 \% \mathrm{Cl}:-3.83$ to $-2.59 ; \mathrm{p}<$ 0.05). Similarly, a significant declining trend was observed in the age standardized mortality rate of India between 1990 and 2019(AAPC: $-1.35 ; 95 \% \mathrm{Cl}:-1.96$ to $-0.75 ; \mathrm{p}<0.05$ ) with highest decline in the period 1998-2005 (AAPC: $-3.52 ; 95 \% \mathrm{Cl}:-4.17$ to $-2.86 ; \mathrm{p}<0.05$ ).

Conclusion:Though the incidence and mortality of cervical cancer declined over past three decades but it is still a major public health problem in India. Information, education and communication activities for girls, boys, parents and community for the prevention and control of cervical cancer should be provided throughout the country.

\section{Background}

Cervical cancer affects the lower most part of women's uterus called "cervix". Human papillomaviruses (HPV) which transmits through sexual contact are associated with almost all of the cervical cancer cases (99\%). Worldwide, cervical cancer is the fourth most common cancer in women (Bray et al, 2018). Despite being a highly preventable cancer, in year 2020,604,127women were reported with cervical cancer and 341,831 women died from the disease globally (GLOBOCAN 2020). Maximum proportion of cervical cancer cases was reported from Asia(58.2\%) and minimum from Northern America region (2.5\%). Recent estimates for 2018 showed that annually 569847 new cervical cancer cases were diagnosed worldwide. Cumulative risk to develop cervical cancer up to age 75 years ranges from $0.88 \%$ in Very high HDI countries to $3.00 \%$ in Low HDI countries (GLOBOCAN 2020). Lowest incidence of cervical cancer was reported in western Asia and the lowest mortality was reposted in Australia-New Zealand region (Arbyn 
et al, 2020). Around 2785 million women are at risk of getting cervical cancer and approximately four fifth of them are from less developed regions. Globally, the age standardized incidence and mortality rates are found to be 13.1 and 6.9 per 100,000 women (ICO, 2019). However, these rates are quite higher among Indian women in comparison to global estimates. In India, the age standardised incidence rate is 14.7 per 100,000 women and the age standardised mortality rate is 9.2 per 100,000 women (ICO, 2019).

Cervical cancer is found to be associated with sexual behaviours such as poor genital hygiene, early age of marriage, multiple sexual partners, repeated pregnancies (Das et al., 1992). Cofactors such as longterm contraceptive use, smoking are associated with HPV infection. Certain women population such as women in correctional facilities are at higher risk for cervical cancer compared to women in the general population (Moghissi \& Mack,1968). Around 453 million Indian women who are aged 15 years and above are at risk of developing cancer (ICO, 2019). Estimates from HPV information centre show that every year 96922 women are diagnosed with cervical cancer and 60078 of them die of this disease in the country. Current data indicates that that cervical cancer is the second most common cancer among females in the country. Low age at marriage, early age at first intercourse, higher parity raises the risk of HPV acquisition among Indian women (Habib and Sanjay, 2012). Although the burden of cervical cancer is increasing largely in the country, deaths due to this can be prevented if it is screened at early stages (Scholes et al, 1996). Cervical cancer mostly affects the women from rural areas with poor socio-economic status (Park et al., 2011). Poor screening is associated with poverty. Lack of screening and treatment has been identified as a factor leading to development of invasive cancer which leads to death (Krishnan et al, 2013; Srinivasan et al, 2018). Although the improvement in the living standard and awareness among women has resulted in a decline in the incidence of cervical cancer in the country, the situation is alarming in the rural settings where the majorities of women are illiterate and have poor hygienic conditions. Additionally, access to medical facilities, poor socio-economic status is also the contributory factors for the spread of carcinoma cervix in rural areas. As, India is on the way to universalize the national level screening programme of cervical cancer it is important to investigate the areas vulnerable to poor screening and trends and patterns in the cervical cancer prevalence in the country. Screening and associated social determinants are vital to understand the need of intervention in a heterogeneous population such as India. There has been a substantial progress in primary prevention strategies and it certainly had an effect on incidence and mortality due to cervical cancer. However, screening for precancerous and cancerous cervical lesions among women aged more than 30 years will be critical in developing country like India to ensure that women receive appropriate diagnostic and treatment services. This study aims to assess trends in incidence and mortality of cervical cancer in India and its states over past three decades for tracking the progress of strategies for the prevention and control of cervical cancer.

\section{Material And Methods}

We have extracted data of cervical cancer Incidence and mortality for 1990 to 2019 from Global Burden of Disease 2019 study. The case definition includes cervical cancer having ICD-10 codes C53, C53.0, C53.1, C53.3, C53.4, C53.8, C53.9, D06, D06.0, D06.1, D06.7, D06.9, D26.0. Data for the incidence and 
Deathrate of cervical cancer for India is extracted from an online tool produced by the IHME which is publicly available called the GHDx (Global Health Data Exchange) query tool

(http://ghdx.healthdata.org/gbd-results-tool). (GBD Collaboration network; 2019) The state level data on burden of cervical cancer is extracted from GBD India Compare tool (https://vizhub.healthdata.org/gbdcompare/india). (GBD India Compare Data Visualization).A total of 59 different data sources are used to model the cause of death estimates for cervical cancer in India. The key sources of data to model the cause of death due to cervical cancer in India includes cancer incidence in five continents by International Agency for Research on Cancer, International Association of Cancer Registries, Population based cancer registries of India and various states, Medical certification of cause of deaths of the country and various states, vital statistics, other surveys on cause of death and published scientific articles. (GBD 2019 Diseases and Injuries Collaborators, 2020).

A spatial map of age standardized incidence and mortality rate has been used at 10-year intervals to understand the trends in cervical cancer incidence and mortality rate over time and space. Further, statewise changesin cervical cancer incidence and mortality rank have been shown through the graph. Joinpoint regression analysis has been applied to compute the magnitude of the time trends in the age standardized incidence and mortality rates of Cervical Cancer, the Average Annual Percent Change (AAPC) and corresponding 95\% Confidence Interval (Cl). By using rates as inputs, the joinpoint regression method identifies the year(s) when a trend change is evident and calculates the annual percentage change (APC) in rates between these trend-change points.

To estimate the APC, the following model is used:

$\log \left(Y_{x}\right)=b_{0}+b_{1} x$, where $\log (\mathrm{Yx})$ is the natural logarithm of the rate in year $\mathrm{x}$.

Then, the APC from year $x$ to year $x+1$ is:

$A P C=\frac{e^{b_{0}+b_{1}(x+1)}-e^{b_{0}+b_{1} x}}{e^{b_{0}+b_{1} x}} * 100=\left(e^{b_{1}}-1\right) * 100$

When no joint point is detected over the period, then APC and AAPC will be same. However, In case of any trend changes over the period, the whole period is segmented by the points with trend change (Kim et. al. 2000). AAPC was calculated as a geometrically weighted average of various annual percent change (APC) values from the regression analysis (Clegg et. al. 2009). For the whole range of our study periods, the average APC (AAPC) is computed using the best model with a maximum of 5 joinpoint pertaining to 6 segments.Joinpoint regression analysis is performed using 'Joinpoint Regression Program' software (version 4.9.0.0) provided by the Surveillance Research Program of the US National Cancer Institute.

\section{Results}




\section{Interpretation}

Figure-1 represents thestate wise incidence of cervical cancer among women from 1990 to 2019.As evident from the maps (Fig. 1)decrement of incidence is not uniform over the time across the states. Some of the states like Jharkhand (-28.47\%) and Gujarat (-23.27\%) shows the highest percentage decline in incidence of cervical cancer in the period 1990-2000. Further in the next decennial (20002010)Himachal Pradesh (-30.87\%) followed by West Bengal (-28.56\%) takes the credit for highest percentage decrement in cervical cancer incidence. Overall, from 1990 to 2019 Jharkhand (-50.22\%) records the highest percentage decrement followed by the Himachal Pradesh (-48.34\%) (appendix Table1). Jammu \& Kashmir report the lowest incidence (7.24 in 1990, 6.31 in 2000, 6.21 in 2010 and 6.13 in 2019) whereas Tamilnadu have the highest incidence (30.92 in 1990, 28.26 in 2000, 21.58 in 2010 and 19.91 in 2019) of cervical cancer from 1990 to 2019.

Figure-2 represents the state-wise mortality of cervical cancer among women for1990-2019. Figure-2 (A, $B, C \& D)$ represents thatmortality of cervical cancer has decreased over the time while thedecrementin the mortalityis not uniform over the time. Jammu \& Kashmir have the lowest mortality level (4.59 per 100,000 women in 1990, 3.93 per 100,000 women in 2000, 3.57 per 100,000 women in 2010 and 3.38 per 100,000 women in 2019) whereas Tamilnadu records the highest mortality due to cervical cancer(20.73 per 100,000 women in 1990, 18.62per 100,000 women in 2000, 13.53 per 100,000 women in 2010 and 11.56per 100,000 women in 2019) from 1990 to 2019.Maps in Fig. 2 show that decrement in the incidence is not uniform across the statesover the time. Some of the states like Jharkhand $(-30.42 \%)$ and Gujarat $(-27.00 \%)$ show the highest percentage decline in mortality due to cervical cancer in the period 1990-2000. Further in the next decennial (2000-2010) West Bengal (-33.83\%) followed by Himachal Pradesh (-33.02\%) have the highest percentage decrement in cervical cancer mortality. Overall, from 1990 to 2019 Jharkhand $(-56.16 \%)$ records the highest percentage decrement followed by the Himachal Pradesh (-53.37\%) (appendix Table2).

\section{Age-standardized cervical cancer incidence transition in India}

Figure 3 indicates the overall variation in the ranks of age-standardized cervical cancer incidence over the three decades (1990 to 2019). Colours given to each state displays the region specification. There are total eight colours and for each, colour specification is given below in the Fig. 3. Dotted line shows the increase in the states ranking(increase in positional rank indicates that the state performs better than some states during the period) from the previous rank and full line shows the state has either remained same in their rank or have slipped below in rank (lowering in positional rank indicates that states haven't improvedmuch in respect to the states whose ranks have increased during period). In Fig. 3 last column indicates the percentage change in incidence of cervical cancer. Among all the states and Union territories, percentage change is negative i.e. all the states and union territories have witnessed a decline in the incidence rateover the time. Percentage decrement in incidence is not uniform across the states which further leads to variation in states rank. Over the thirty years,ranks of only four sates namely Tamil Nadu (1st rank, -35.61 percentage change), Mizoram (3rd rank, -20.44 percentage change), Andhra 
Pradesh (22nd rank, -30.77 percentage change) and Jammu \& Kashmir \&Ladakh (32nd rank, -15.33 percentage change) have remained same and the ranks of remaining states have changed. First rank indicates the highest incidence of cervical cancer and last (32nd) rank indicates the lowest value in agestandardized cervical cancer incidence. Highest percentage change in age standardized incidence is found in Jharkhand (-50.21\%, 2nd rank in 1990 to 10th rank in 2019) followed by Himanchal Pradesh $(-48.34 \%$, 4th rank in 1990 to 17 th rank in 2019) in contrast to the lowest change in incidence is observed in the state Uttar Pradesh $(-7.86 \%, 19$ st rank in 1990 to 7th rank in 2019) followed by Karnataka (-8.24\%, 6th rank in 1990 to 2nd rank in 2019). Only a single state namely Rajasthan have shown the increase in the incidence value over the time (0.43\%, 28th rank in 1990 to 16 th rank in 2019). In year 1990, 11 states rank lower than the national average (India 12th rank, incidence 16.65 per 100000) but in 2019 a total of 10 states rank lower than the national average (India 11th rank, incidence 13.1 per 100000).

Among seven northern states, half of the states (Himachal Pradesh, Delhi, Uttarakhand) have moved upward in their rank and other states like Punjab, Rajasthan, Haryana) have (Jammu \& Kashmir and Ladakh) remained same in their rank, in north-eastern region of the country two states i.e.Arunachala Pradesh and Assam rank have decreased, however Mizoram has remained same in their positional rank and ranks of these five statesi.e. Nagaland, Meghalaya, Tripura, Sikkim, Manipur have increased.

\section{Age-standardized cervical cancer mortality transition in India}

Figure 4 indicates the variation in ranks of age-standardized cervical cancer mortality among all ages over the three decades (1990 to 2019). The last column indicates the percentage change in mortality of cervical cancer. Across all states and Union territories percentage change is negative indicating all the states and union territories have witnessed a decline in the mortality over the time. The variation in the state ranking indicates that percentage decrement in mortality is not uniform.Overall, Tamil Nadu has performed worst in case of age-standardized cervical cancer incidence 30.92 (Cl: $15.78-41.77$ ) in 1990 to 19.91 (Cl: 11.27 - 26.83) in 2019 and mortality 20.73 (Cl: 10.88 - 27.6) in 1990 to 11.57 (Cl: 6.31 15.59)) per 100,000 females in 2019 both. Whereas Jammu \& Kashmir \& Ladakh have performedwell in terms of age-standardized cervical cancer incidence 7.24 (Cl: 4.48 - 18.14) in 1990 to 6.13 (Cl: 3.95 15.71) in 2019 and mortality 4.6 (Cl: 2.85 - 12.09) in 1990 to 3.39 (Cl: $2.21-8.78$ ) per 100,000 females in 2019. Both the highest and lowest performing states have maintained their rank over the period. In the year 1990 , total 11 states have ranks lower than the national average (India $12^{\text {th }}$ rank, mortality 10.9 per 100000 females) but in 2019 only 10 states show lower rankings than the national average (India $11^{\text {th }}$ rank, mortality 7.38 per 100000 females).

Table 1: Trends in incidence and mortality of Cervical Cancerin India from 1990 to 2019 using Joinpoint Regression Analysis 


\begin{tabular}{|llllll|}
\hline \multicolumn{2}{l}{ Age Standardised Incidence rate } & \multicolumn{3}{l|}{ Age Standardised Mortality rate } \\
\hline Segment & Year & APC* $(95 \%$ C.I.) & Segment & Year & APC* $(95 \%$ C.I.) \\
\hline $\mathbf{1}$ & $1990-1995$ & $-1.24^{\star}(-2.07,-0.40)$ & $\mathbf{1}$ & $1990-1995$ & $-1.58^{*}(-2.46,-0.68)$ \\
\hline $\mathbf{2}$ & $1995-1998$ & $1.47(-2.31,5.39)$ & $\mathbf{2}$ & $1995-1998$ & $0.95(-3.05,5.11)$ \\
\hline $\mathbf{3}$ & $1998-2005$ & $-3.22^{\star}(-3.83,-2.59)$ & $\mathbf{3}$ & $1998-2005$ & $-3.52^{\star}(-4.17,-2.86)$ \\
\hline $\mathbf{4}$ & $2005-2012$ & $-0.84^{*}(-1.47,-0.20)$ & $\mathbf{4}$ & $2005-2012$ & $-1.67^{\star}(-2.34,-0.99)$ \\
\hline $\mathbf{5}$ & $2012-2015$ & $2.49(-1.33,6.45)$ & $\mathbf{5}$ & $2012-2015$ & $2.11(-1.94,6.32)$ \\
\hline $\mathbf{6}$ & $2015-2019$ & $-0.16(-1.35,1.05)$ & $\mathbf{6}$ & $2015-2019$ & $-0.96(-2.22,0.31)$ \\
\hline AAPC* & $1990-2019$ & $-0.82^{*}(-1.39,-0.25)$ & AAPC* & $1990-2019$ & $-1.35^{\star}(-1.96,-0.75)$ \\
\hline
\end{tabular}

Note: *, Indicates that the Annual Percent Change (APC) is significantly different from zero at the alpha = 0.05 level; APC, annual percentage change; AAPC, average annual percent change; $\mathrm{Cl}$, confidence interval

Trends in Age-Standardized Cervical Cancer Incidence and Death Rates Using Joinpoint Regression Analysis across India

Table 1 shows the APC and AAPC of incidence and mortality due to cervical cancer in India from 1990 to 2019). The regression model shows a significant declining trend in India between 1990 and 2019 for age standardized incidence rate (AAPC: $-0.82 ; 95 \% \mathrm{Cl}:-1.39$ to $-0.25 ; \mathrm{p}<0.05$ ) with highest decline in the period 1998-2005 (AAPC: -3.22 ; 95\%Cl: -3.83 to -2.59 ; $p<0.05$ ) (Table 1, Figure 5a). Similarly, a significant declining trend has been observed in the age standardized mortality rate India between 1990 and 2019 (AAPC: $-1.35 ; 95 \% \mathrm{Cl}:-1.96$ to $-0.75 ; \mathrm{p}<0.05$ ) with highest decline in the period 1998-2005 (AAPC: $-3.52 ; 95 \% \mathrm{Cl}:-4.17$ to $-2.86 ; p<0.05$ ) (Table 1, Figure $5 b$ ).

Table 2:Age standardised Incidence and death rates of cervical cancer for India and its states in 2019 and their Average Annual Percentage Change (AAPC) from 1990 to 2019 


\begin{tabular}{|c|c|c|c|c|}
\hline \multirow[t]{2}{*}{ State } & \multicolumn{2}{|l|}{ Incidence } & \multicolumn{2}{|l|}{ Death } \\
\hline & $\begin{array}{l}\text { Rates in } 2019,95 \% \text { UI } \\
\text { (per } 100000 \text { females) }\end{array}$ & $\begin{array}{l}\text { AAPC, } 95 \% \mathrm{Cl} \\
(\%, 1990- \\
2019)\end{array}$ & $\begin{array}{l}\text { Rates in } 2019,95 \% \text { UI } \\
\text { (per } 100000 \text { females) }\end{array}$ & $\begin{array}{l}\text { AAPC, } 95 \% \mathrm{Cl} \\
(\%, 1990- \\
2019)\end{array}$ \\
\hline India & $13.10(10.18,17.09)$ & $\begin{array}{l}-0.82^{*}(-1.39 \\
-0.25)\end{array}$ & $7.38(5.71,10.13)$ & $\begin{array}{l}-1.35^{\star}(-1.96 \\
-0.75)\end{array}$ \\
\hline $\begin{array}{l}\text { Andhra } \\
\text { Pradesh }\end{array}$ & $9.81(6.34,16.96)$ & $\begin{array}{l}-1.26 *(-1.42 \\
-1.09)\end{array}$ & $5.34(3.50,9.67)$ & $\begin{array}{l}-1.75^{\star}(-1.88 \\
-1.61)\end{array}$ \\
\hline $\begin{array}{l}\text { Arunachal } \\
\text { Pradesh }\end{array}$ & $14.01(9.20,20.68)$ & $\begin{array}{l}-1.05^{\star}(-1.16 \\
-0.93)\end{array}$ & $7.99(5.52,10.95)$ & $\begin{array}{l}-1.51 *(-1.63 \\
-1.39)\end{array}$ \\
\hline Assam & $10.68(7.49,19.26)$ & $\begin{array}{l}-0.50(-1.23 \\
0.24)\end{array}$ & $6.39(4.63,12.52)$ & $\begin{array}{l}-1.19 *(-1.73 \\
-0.64)\end{array}$ \\
\hline Bihar & $11.46(7.79,18.89)$ & $\begin{array}{l}-0.49 *(-0.55 \\
-0.43)\end{array}$ & $6.55(4.49,11.13)$ & $\begin{array}{l}-1.01 *(-1.12 \\
-0.89)\end{array}$ \\
\hline Chhattisgarh & $14.81(10.36,20.30)$ & $\begin{array}{l}-0.92 *(-1.43 \\
-0.41)\end{array}$ & $8.71(6.30,12.97)$ & $\begin{array}{l}-1.14^{\star}(-1.64 \\
-0.64)\end{array}$ \\
\hline Delhi & $11.87(8.50,15.78)$ & $\begin{array}{l}-2.07 *(-2.51 \\
-1.62)\end{array}$ & $7.11(4.81,9.26)$ & $\begin{array}{l}-2.63 *(-3.42 \\
-1.82)\end{array}$ \\
\hline Goa & $7.02(4.55,11.46)$ & $\begin{array}{l}-1.31 *(-1.67 \\
-0.96)\end{array}$ & $3.58(2.35,6.27)$ & $\begin{array}{l}-1.99 *(-2.05 \\
-1.93)\end{array}$ \\
\hline Gujarat & $13.26(9.31,18.80)$ & $\begin{array}{l}-0.53(-1.47 \\
0.42)\end{array}$ & $7.12(5.04,10.56)$ & $\begin{array}{l}-1.29 *(-2.10 \\
-0.47)\end{array}$ \\
\hline Haryana & $7.85(5.20,15.03)$ & $\begin{array}{l}-0.62(-1.65 \\
0.42)\end{array}$ & $4.32(2.85,9.54)$ & $\begin{array}{l}-1.07(-2.21 \\
0.10)\end{array}$ \\
\hline $\begin{array}{l}\text { Himachal } \\
\text { Pradesh }\end{array}$ & $11.66(8.05,16.25)$ & $\begin{array}{l}-2.30 *(-2.82 \\
-1.77)\end{array}$ & $6.49(4.70,8.81)$ & $\begin{array}{l}-2.59 *(-3.33 \\
-1.85)\end{array}$ \\
\hline $\begin{array}{l}\text { Jammu \& } \\
\text { Kashmir and } \\
\text { Ladakh }\end{array}$ & $6.13(3.95,15.71)$ & $\begin{array}{l}-0.62 *(-0.76 \\
-0.48)\end{array}$ & $3.39(2.21,8.78)$ & $\begin{array}{l}-1.06 *(-1.17 \\
-0.94)\end{array}$ \\
\hline Jharkhand & $13.18(9.84,18.37)$ & $\begin{array}{l}-2.21 *(-2.57 \\
-1.85)\end{array}$ & $7.87(5.84,10.94)$ & $\begin{array}{l}-2.74 *(-3.06 \\
-2.42)\end{array}$ \\
\hline Karnataka & $19.83(11.86,27.51)$ & $\begin{array}{l}-0.31(-1.00 \\
0.39)\end{array}$ & $11.14(6.67,15.10)$ & $\begin{array}{l}-0.77(-1.61, \\
0.07)\end{array}$ \\
\hline Kerala & $9.35(6.57,12.92)$ & $\begin{array}{l}-1.07(-2.21 \\
0.08)\end{array}$ & $4.77(3.29,6.49)$ & $\begin{array}{l}-1.88 *(-2.41 \\
-1.34)\end{array}$ \\
\hline $\begin{array}{l}\text { Madhya } \\
\text { Pradesh }\end{array}$ & $13.41(9.77,17.92)$ & $\begin{array}{l}-0.64 *(-0.85 \\
-0.44)\end{array}$ & $7.88(5.85,10.47)$ & $\begin{array}{l}-1.05^{\star}(-1.25 \\
-0.86)\end{array}$ \\
\hline Maharashtra & $16.75(11.08,22.65)$ & $\begin{array}{l}-0.41(-0.94 \\
0.13)\end{array}$ & $9.26(6.22,12.29)$ & $\begin{array}{l}-1.04^{*}(-1.59 \\
-0.49)\end{array}$ \\
\hline
\end{tabular}




\begin{tabular}{|c|c|c|c|c|}
\hline Manipur & $9.25(5.90,14.93)$ & $\begin{array}{l}-0.87 *(-1.13 \\
-0.61)\end{array}$ & $5.59(3.78,8.86)$ & $\begin{array}{l}-1.10 *(-1.68, \\
-0.51)\end{array}$ \\
\hline Meghalaya & $11.40(7.59,16.99)$ & $\begin{array}{l}-1.14 *(-1.56 \\
-0.71)\end{array}$ & $6.84(4.86,9.84)$ & $\begin{array}{l}-1.42 *(-1.61, \\
-1.24)\end{array}$ \\
\hline Mizoram & $18.99(9.50,29.21)$ & $\begin{array}{l}-0.72^{\star}(-1.26 \\
-0.18)\end{array}$ & $10.90(5.64,16.15)$ & $\begin{array}{l}-1.11 *(-1.72, \\
-0.50)\end{array}$ \\
\hline Nagaland & $12.95(7.59,19.42)$ & $\begin{array}{l}-1.23^{*}(-1.36 \\
-1.10)\end{array}$ & $7.57(4.81,10.93)$ & $\begin{array}{l}-1.55^{\star}(-1.67 \text {, } \\
-1.42)\end{array}$ \\
\hline Odisha & $7.10(4.42,17.34)$ & $\begin{array}{l}-1.32^{\star}(-1.96 \\
-0.67)\end{array}$ & $4.22(2.64,10.63)$ & $\begin{array}{l}-1.66 *(-1.88, \\
-1.44)\end{array}$ \\
\hline $\begin{array}{l}\text { Other Union } \\
\text { Territories }\end{array}$ & $9.50(6.34,14.04)$ & $\begin{array}{l}-1.44^{*}(-1.74 \\
-1.14)\end{array}$ & $5.14(3.56,7.72)$ & $\begin{array}{l}-1.85 *(-2.01, \\
-1.68)\end{array}$ \\
\hline Punjab & $13.00(9.65,17.82)$ & $\begin{array}{l}-0.43^{*}(-0.83 \\
-0.02)\end{array}$ & $7.14(5.10,9.72)$ & $\begin{array}{l}-0.95^{\star}(-1.46, \\
-0.44)\end{array}$ \\
\hline Rajasthan & $11.77(8.32,17.92)$ & $\begin{array}{l}0.05(-0.71, \\
0.82)\end{array}$ & $6.26(4.25,10.45)$ & $\begin{array}{l}-0.65(-1.53 \\
0.25)\end{array}$ \\
\hline Sikkim & $9.72(6.61,14.78)$ & $\begin{array}{l}-1.35^{\star}(-1.78 \\
-0.93)\end{array}$ & $5.47(3.90,7.88)$ & $\begin{array}{l}-1.85^{\star}(-2.05, \\
-1.65)\end{array}$ \\
\hline Tamil Nadu & $19.91(11.27,26.83)$ & $\begin{array}{l}-1.49 *(-1.94 \\
-1.04)\end{array}$ & $11.57(6.31,15.59)$ & $\begin{array}{l}-1.98 *(-2.29, \\
-1.67)\end{array}$ \\
\hline Telangana & $9.76(6.03,16.26)$ & $\begin{array}{l}-1.47 *(-1.52 \\
-1.41)\end{array}$ & $5.07(3.23,9.03)$ & $\begin{array}{l}-2.08 *(-2.18, \\
-1.98)\end{array}$ \\
\hline Tripura & $10.64(7.00,15.99)$ & $\begin{array}{l}-1.36^{\star}(-1.51 \\
-1.21)\end{array}$ & $6.25(4.36,9.15)$ & $\begin{array}{l}-1.70 *(-1.82, \\
-1.57)\end{array}$ \\
\hline Uttar Pradesh & $13.48(9.21,21.21)$ & $\begin{array}{l}-0.26(-0.74 \\
0.22)\end{array}$ & $7.79(5.43,13.89)$ & $\begin{array}{l}-0.72 *(-1.15, \\
-0.30)\end{array}$ \\
\hline Uttarakhand & $12.32(8.80,19.28)$ & $\begin{array}{l}-1.22^{\star}(-1.33 \\
-1.11)\end{array}$ & $6.83(4.94,11.45)$ & $\begin{array}{l}-1.74^{\star}(-1.83, \\
-1.66)\end{array}$ \\
\hline West Bengal & $9.67(7.06,13.94)$ & $\begin{array}{l}-1.11 *(-1.87 \\
-0.35)\end{array}$ & $5.24(3.89,7.89)$ & $\begin{array}{l}-1.83^{*}(-3.02, \\
-0.62)\end{array}$ \\
\hline
\end{tabular}

Trends in Age-Standardized Cervical Cancer Incidence and Death Rates Using Joinpoint

\section{Regression Analysis across the states of India}

Results from table 2 shows the Age standardized rates and AAPC of Cervical Cancer incidence and Death in India and its states in 1990 - 2019. The age - standardized incidence and death rates of cervical cancer in India is found to be 13.10 (95\% UI 10.18,17.09) and 7.38 (95\% UI 5.71,10.13) per 100,000 females respectively. The highest age standardized incidence rate of Cervical Cancer is observed in Tamilnadu 
19.91 (95\% UI 11.27,26.83), followed by Karnataka 19.83 (95\% UI 11.86,27.51) and Mizoram 18.99 (95\% UI 9.50,29.21) per 100,000 females. However, the lowest age standardized Incidence rate of Cervical Cancer is observed in Jammu \& Kashmir and Ladakh 6.13 (95\% UI 3.95,15.71), followed by Goa 7.02 (95\% UI 4.55,11.46) and Odisha 7.10 (95\% UI 4.42,17.34) per 100,000 females. A similar pattern is observed in the mortality among states as observed in Incidence. The highest age standardized Death rate of Cervical Cancer is observed in Tamilnadu 11.57 (95\% UI 6.31,15.59), followed by Karnataka 11.14 (95\% UI 6.67,15.10) and Mizoram 10.90 (95\% UI 5.64,16.15) per 100,000 females. However, the lowest age standardized Death rate of Cervical Cancer is observed in Jammu \& Kashmir and Ladakh 3.39 (95\% UI 2.21,8.78) followed by Goa 3.58 (95\% UI 2.35,6.27) and Odisha 4.22 (95\% UI 2.64,10.63) per 100,000 females.

For Incidence, all of the states have shown a significant declining trend except Gujarat (AAPC: -0.53; $95 \% \mathrm{Cl}:-1.47$ to $0.42 ; \mathrm{p}>0.05$ ), Assam (AAPC: $-0.50 ; 95 \% \mathrm{Cl}:-1.23$ to $0.24 ; \mathrm{p}>0.05$ ) , Haryana (AAPC: $-0.62 ; 95 \% \mathrm{Cl}:-1.65$ to $0.42 ; \mathrm{p}>0.05$ ), Karnataka (AAPC: $-0.31 ; 95 \% \mathrm{Cl}:-1.00$ to $0.39 ; \mathrm{p}>0.05$ ), Maharashtra (AAPC: $-0.41 ; 95 \% \mathrm{Cl}:-0.94$ to $0.13 ; \mathrm{p}>0.05$ ) ,Uttar Pradesh (AAPC: $-0.26 ; 95 \% \mathrm{Cl}:-0.74$ to $0.22 ; p>0.05$ ) and Kerala (AAPC: $-1.07 ; 95 \% \mathrm{Cl}:-2.21$ to $0.08 ; p>0.05$ ) where non-significant declining trend was observed and Rajasthan (AAPC: $0.05 ; 95 \% \mathrm{Cl}$ : -0.71 to $0.82 ; \mathrm{p}>0.05$ ) where non-significant increasing trend is observed.(Table 2, Supplementary Fig 1)All of the states have shown a significant declining trend in mortality except Haryana (AAPC: $-1.07 ; 95 \% \mathrm{Cl}:-2.21$ to $0.10 ; p>0.05$ ), Karnataka (AAPC: $-0.77 ; 95 \% \mathrm{Cl}:-1.61$ to $0.07 ; p>0.05$ ) and Rajasthan (AAPC: $-0.65 ; 95 \% \mathrm{Cl}:-1.53$ to $0.25 ; \mathrm{p}>0.05$ ), where non-significant declining trend is observed.(Table 2, Supplementary Fig 2)

\section{Discussion}

In this study we found that there has been significant decline in the incidence and mortality of cervical cancer over past three decades in India; This corroborates with studies conducted by various other researchers (Sankaranarayanan et al., 2007; Nandakar et al., 2009; Forman et al., 2012;Bobdey et al., 2016). Whereas in high-income countries, cervical cancer incidence and mortality have decreased by more than half over the past 30 years after the introduction of formalized screening programmes (Cancer Council, 2016).Recent evidences suggest that factors such as socio-economic development and highincome countries type life-style related transitions underpin changes in cancer risk, reducing the cervical cancer rates in countries with emerging economies (Bray et al., 2012; Dhillon et al., 2011). A trend of decline in the incidence rates in urban areas truly represent the societal changes which is not reflected in rural areas of India (Badwe et al., 2014).

Based on a complete and reliable data obtained from Bombay Cancer Registry, a paper emphasizes that the decline in the incidence of cervical is not due to change in registration practice but solely attributable to epidemiological transition (Knaul et al., 2012; Vaccarella et al., 2019). In lower-middle income countries, a decline in the cervical cancer incidence has been due to opportunistic screening (Sriplung et al., 2014). Bobdey and colleagues have found that data from most of the major Indian cancer registries indicated having decreasing trend of cervical cancer, however, the decrease was small (Bobdey et al., 
2016).Further, research have also highlighted that the decline in the incidence of cervical cancer is also because of lack of an organized mass-screening program for early detection of cervical cancer in India (Murthy et al., 2005).

Notwithstanding with the caveat of the estimates from various information, the absolute number of cases of cervix uteri cancer has increased over time (GLOBCAN)(471000 in 2000, 529000 in 2008, 570,000 in 2018) (Arbyn et al., 2011; Parkin et al., 2001). The rising age at marriage, increase in the age at first term pregnancy, lowering parity could have contributed in reducing the risk of HPV acquisition, decreasing the incidence of cervical cancer in India. Further, vaccination could have lead to this significant decline in the burden of cervical cancer. As evident from developed countries, screening and vaccination has been identified as preventive measure in reducing the burden of cervical cancer (Jamal et al., 2010). Consistent with our findings, a study conducted across 38 countries found a substantial decrease in the age-standardized incidence rates in the highest-income countries. However, these rates were found to increase or stabilized rates were visible in lower-resourced settings (Vaccarella et al., 2013).

This study reports a substantial decline in the mortality due to cervical cancer in the country. This finding is consistent with other studies as well. The decline in the morality is mainly attributable to improved health facility, screening and vaccination coverage. Arbyn reported that the proportion of deaths due to cervical cancer has decreased from 8.2\% in 2008 to 7.5\% in 2018 (Arbyn et al., 2020). Chauhan and colleagues found that introducing HPV vaccination alone led to a $60 \%$ decline in the cervical cancer related mortality in comparison to those without any vaccination and screening (Chauhan et al., 2020).This study reveals that different screening strategies have a varying reduction in lifetime occurrence of cervical cancer caused by HPV from 16-61\% and reducing mortality due to cervical cancer from $28-70 \%$ (Chauhan et al., 2020). Furthermore, a successful organized and opportunistic screening has led to a substantial decline in last 50 years in cervical cancer morbidity and mortality in high- and middle-income countries (Franco et al., 2003).

There has been - 21.32 percentage change in the incidence of cervical cancer in the period 1990-2019. Similarly, a change of -32.29 percentage point is observed in the mortality due to cervical cancer in the country. The trends observed in the cervical cancer incidence and mortality in the country over the period is likely due to factors such as population ageing, changes in knowledge and literacy, early screening improved access to health care and other risk factors. Studies have also highlighted the lack of inadequate and incomplete information on deaths leading to inaccuracy of mortality statistics and trends. Reproductive risk factors such as later age at first birth, lower parity is inversely related to decreasing age-standardized incidence rates (Dhillon et al., 2011). The age-standardized incidence and death rates of cervical cancer is found to be 13.10 and 7.38 per 100,000 females. Consistent with our findings, researchers found the age-standardized incidence and mortality rates of cervical cancer to be 14.7 and 9.2 per 100,000 among Indian women (Balasubramaniam et al., 2020). Similarly, researchers at George institute also found the age-standardized incidence and mortality rates of cervical cancer to be 22 and 12.4 per 100,000 women. Rank of age-standardized cervical cancer incidence rate has decreased significantly in states like Arunachal Pradesh and Assam.A geographical difference reflected in the 
incidence of mortality is due to differences in exposure to risk factors and serious inequalities in access to adequate screening and effective cancer treatment facilities.

Even after more than a decade of introduction of HPV vaccines, the prevalence of cervical cancer is quite alarming. In India, Universal cervical cancer screening is an unmet need (Aoki et al., 2020). Fourth round of National Family Health Survey estimates that only $22.3 \%$ of eligible women received cervical cancer screening during 2015-16 (NFHS-4, 2015-16) The associated mortality with the Cervical cancer in India is one of the highest in the world (Das et al.,1992; Sureshkumar et al., 2015; Patel et al., 2014). Studies have reported that the overall knowledge and awareness about cervical cancer, HPV and HPV vaccination in India is very poor. Researchers are of the opinion that factors such as societal, religious and prejudice ideas, socio-economic status including lack of knowledge, awareness and attitude affect the HPV vaccination in India.Present study has few limitations. First, Although GBD study has subsumes various methods to improve the quality of data by adjusting for missing or incomplete data, but we can't rule out the possibility of some inaccuracy in the mortality data. Second, this is an ecological study, hence interpretations from this study are true at population levels but at individual level they do not necessarily holds.

\section{Conclusion}

This study concludes that overall incidence and mortality of cervical cancer showed a significant decreasing trend in India between 1990 and 2019, highest decline in the incidence and mortality rates were reported in the period 1998-2005. The highest incidence and mortality of cervical cancer was reported in Tamilnadu and lowest in Jammu \& Kashmir and Ladakh during 1990 \& 2019. The highest percentage decrement in incidence of cervical cancer was reported in Jharkhand and lowest in Jammu \& Kashmir during the study period. The highest percentage decrement in cervical cancer mortality was seen in Jharkhand from 1990 to 2019.

Though the incidence and mortality of cervical cancer declined over past three decades but it is still a major public health problem in India. Information, education and communication activities for girls, boys, parents and community regarding the risk factors of cervical cancer, mode of transmission, screening programme, HPV, HPV vaccination and treatment modalities should be provided throughout the country. HPV vaccine should be included in the national immunization program to improve its availability and accessibility to all the eligible beneficiaries. Cervical cancer screening facility should be available at peripheral level for early diagnosis of pre-cancerous condition. Involvement of non-government organizations can play key role in primary, secondary and tertiary level of prevention for cervical cancer.

\section{Declarations}

Ethics approval and consent to participate: Not applicable

Consent for publication: Not applicable

Page 12/22 
Availability of Data and Materials: Data was extracted from online tool produced by the IHME which is publicly available called the GHDx (Global Health Data Exchange) query tool (http://ghdx.healthdata.org/gbd-results-tool)

Competing interest: The authors declare that they have no conflict of interest.

Funding: No funding available

Author's contribution: RPJ, DD and MS contributed in conceptualizing the study. RPJ, NS, PP, DD, KB and MS were responsible for the analysis. All authors contributed to the interpretation of the data, and critically revised all versions of the manuscript and approved the final version.

Acknowledgements: We thank the Institute for Health Metrics and Evaluation (IHME) and the University of Washington for providing the GBD estimates.

\section{References}

1. Aoki, E. S., Yin, R., Li, K., Bhatla, N., Singhal, S., Ocviyanti, D., ... \& Termrungruanglert, W. (2020). National screening programs for cervical cancer in Asian countries. Journal of gynecologic oncology, 31(3).

2. Arbyn, M., Castellsagué, X., de Sanjosé, S., Bruni, L., Saraiya, M., Bray, F., \&Ferlay, J. (2011). Worldwide burden of cervical cancer in 2008. Annals of oncology, 22(12), 2675-2686.

3. Arbyn, M., Weiderpass, E., Bruni, L., de Sanjosé, S., Saraiya, M., Ferlay, J., \& Bray, F. (2020). Estimates of incidence and mortality of cervical cancer in 2018: a worldwide analysis. The Lancet Global Health, 8(2), e191-e203.

4. Badwe, R. A., Dikshit, R., Laversanne, M., \& Bray, F. (2014). Cancer incidence trends in India. Japanese journal of clinical oncology, 44(5), 401-407.

5. Balasubramaniam, G., Gaidhani, R. H., Khan, A., Saoba, S., Mahantshetty, U., \& Maheshwari, A. (2020). Survival rate of cervical cancer from a study conducted in India. Indian Journal of Medical Sciences, 1-10.

6. Bobdey, S., Sathwara, J., Jain, A., \&Balasubramaniam, G. (2016). Burden of cervical cancer and role of screening in India. Indian journal of medical and paediatric oncology: official journal of Indian Society of Medical \& Paediatric Oncology, 37(4), 278.

7. Bray, F., Jemal, A., Grey, N., Ferlay, J., \& Forman, D. (2012). Global cancer transitions according to the Human Development Index (2008-2030): a population-based study. The lancet oncology, 13(8), 790801.

8. Bray F, Ferlay J, Soerjomataram I, Siegel RL, Torre LA, Jemal A. Global cancer statistics 2018 : GLOBOCAN estimates of incidence and mortality worldwide for 36 cancers in 185 countries. CA Cancer J Clin 2018; 68: 394-424. *https://gco.iarc.fr/today/data/factsheets/cancers/23-Cervix-uterifact-sheet.pdf [GLOBOCAN 2020] 
9. Cancer Council Australia Cervical Cancer Screening Guidelines Working Party. National Cervical screening program: guidelines for the management of screen-detected abnormalities, screening in specific populations and investigation of abnormal vaginal bleeding. Cancer Council: Sydney, 2016. https://wiki.cancer.org. au/australia/Guidelines:Cervical_cancer/Screening (accessed July 4, 2018).

10. Chauhan, A. S., Prinja, S., Srinivasan, R., Rai, B., Malliga, J. S., Jyani, G., ... \& Ghoshal, S. (2020). Cost effectiveness of strategies for cervical cancer prevention in India. PloS one, 15(9), e0238291.

11. Clegg, L.X.; Hankey, B.F.; Tiwari, R.; Feuer, E.J.; Edwards, B.K. Estimating average annual per cent change intrend analysis. Stat. Med. 2009, 28, 3670-3682.

12. Das, B. C., Sharma, J. K., Gopalkrishna, V., Das, D. K., Singh, V., Gissmann, L., ... \& Luthra, U. K. (1992). A high frequency of human papillomavirus DNA sequences in cervical carcinomas of Indian women as revealed by Southern blot hybridization and polymerase chain reaction. Journal of medical virology, 36(4), 239-245.

13. Das, B. C., Gopalkrishna, V., Sharma, J. K., Roy, M., \& Luthra, U. K. (1992). Human papillomavirus DNA in urine of women with preneoplastic and neoplastic cervical lesions. The Lancet, 340(8832), 14171418.

14. Dhillon, P. K., Yeole, B. B., Dikshit, R., Kurkure, A. P., \& Bray, F. (2011). Trends in breast, ovarian and cervical cancer incidence in Mumbai, India over a 30-year period, 1976-2005: an age-period-cohort analysis. British Journal of Cancer, 105(5), 723-730.

15. Dhillon, P. K., Mathur, P., Nandakumar, A., Fitzmaurice, C., Kumar, G. A., Mehrotra, R., ... \&Dandona, L. (2018). The burden of cancers and their variations across the states of India: the Global Burden of Disease Study 1990-2016. The Lancet Oncology, 19(10), 1289-1306.

16. Farooqui, H. H., \&Zodpey, S. (2012). Cervical cancer control in India: Taking evidence to action. Journal of public health policy, 33(2), 165-172.

17. Franco, E. L., Schlecht, N. F., \&Saslow, D. (2003). The epidemiology of cervical cancer. The Cancer Journal, 9(5), 348-359.

18. Forman, D., de Martel, C., Lacey, C. J., Soerjomataram, I., Lortet-Tieulent, J., Bruni, L., ... \&Franceschi, S. (2012). Global burden of human papillomavirus and related diseases. Vaccine, 30, F12-F23.

19. GBD 2019 Diseases and Injuries Collaborators. Global burden of 369 diseases and injuries in 204 countries and territories, 1990-2019: a systematic analysis for the Global Burden of Disease Study 2019. Lancet 2020; 396: 1204-22.

20. Global Burden of Disease Collaborative Network. Global Burden of Disease Study 2019 (GBD 2019) Results. Seattle, United States: Institute for Health Metrics and Evaluation (IHME), 2020. Available from http://ghdx.healthdata.org/gbd-results-tool

21. ICO Information Centre on HPV and cancer. Human Papillomavirus and Related Diseases in India (Summary Report 2019-06-17); 2019. http://cancerindia.org.in/wpcontent/uploads/2017/11/Cervical.pdf

22. Indian Council of Medical Research, Public Health Foundation of India, and Institute for Health Metrics and Evaluation. GBD India Compare Data Visualization. New Delhi: ICMR, PHFI, and IHME; 
2017. Available from http://vizhub.healthdata.org/gbd-compare/india (Accessed [15.01.2021])

23. International Institute for Population Sciences (IIPS) and ICF. 2017. National Family Health Survey (NFHS-4), 2015-16: India. Mumbai: IIPS.

24. Jemal, A., Center, M. M., DeSantis, C., \& Ward, E. M. (2010). Global patterns of cancer incidence and mortality rates and trends. Cancer Epidemiology and Prevention Biomarkers, 19(8), 1893-1907.

25. Kim, H.J.; Fay, M.P.; Feuer, E.J.; Midthune, D.N. Permutation tests for joinpoint regression with applicationsto cancer rates. Stat. Med. 2000, 19, 335-351.

26. Knaul, F. M., Adami, H. O., Adebamowo, C., Arreola-Ornelas, H., Berger, A. J., Bhadelia, A., ... \&Frenk, J. (2012). The global cancer divide: an equity imperative. In Closing the cancer divide: an equity imperative (pp. 29-60). Harvard Global Equity Initiative, Cambridge, MA.

27. Krishnan, S., Madson, E., Porterfield, D., \& Varghese, B. (2013). Advancing cervical cancer prevention in India: insights from research and programs.

28. Lortet-Tieulent, J., Saracci, R., Conway, D. I., Straif, K., \& Wild, C. P. (2019). Reducing social inequalities in cancer: evidence and priorities for research.

29. Moghissi, K. S., \& Mack, H. C. (1968). Epidemiology of cervical cancer: study of a prison population. American journal of obstetrics and gynecology, 100(5), 607-614.

30. Murthy, N. S., Chaudhry, K., \& Saxena, S. (2005). Trends in cervical cancer incidence-Indian scenario. European journal of cancer prevention, 14(6), 513-518.

31. Nandakumar, A., Ramnath, T., \& Chaturvedi, M. (2009). The magnitude of cancer cervix in India. Indian J Med Res, 130(3), 219-221.

32. Park, M. J., Park, E. C., Choi, K. S., Jun, J. K., \& Lee, H. Y. (2011). Sociodemographic gradients in breast and cervical cancer screening in Korea: the Korean National Cancer Screening Survey (KNCSS) 2005-2009. BMC cancer, 11(1), 1-8.

33. Patel, K. R., Vajaria, B. N., Begum, R., Desai, A., Patel, J. B., Shah, F. D., ... \& Patel, P. S. (2014). Prevalence of high-risk human papillomavirus type 16 and 18 in oral and cervical cancers in population from G ujarat, W est I ndia. Journal of oral pathology \& medicine, 43(4), 293-297.

34. Sankaranarayanan, R., Esmy, P. O., Rajkumar, R., Muwonge, R., Swaminathan, R., Shanthakumari, S., ... \& Cherian, J. (2007). Effect of visual screening on cervical cancer incidence and mortality in Tamil Nadu, India: a cluster-randomised trial. The Lancet, 370(9585), 398-406.

35. Scholes, D., Stergachis, A., Heidrich, F. E., Andrilla, H., Holmes, K. K., \&Stamm, W. E. (1996). Prevention of pelvic inflammatory disease by screening for cervical chlamydial infection. New England Journal of Medicine, 334(21), 1362-1366. Srinivasan S, Johari V, Jesani A. Cervical cancer screening in India. Ethics dumping. Springer; 2018. p. 33e48

36. Sriplung, H., Singkham, P., lamsirithaworn, S., Jiraphongsa, C., \&Bilheem, S. (2014). Success of a cervical cancer screening program: trends in incidence in songkhla, southern Thailand, 1989-2010, and prediction of future incidences to 2030. Asian Pacific Journal of Cancer Prevention, 15(22), $10003-10008$. 
37. Sureshkumar, B. T., Shanmughapriya, S., Das, B. C., \&Natarajaseenivasan, K. (2015). A populationbased study of the prevalence of HPV in three districts of Tamil Nadu, India. International Journal of Gynecology\& Obstetrics, 129(1), 58-61.

38. The George Institute, Cervical Cancer in India: Challenge and Opportunitieshttps://cdn.georgeinstitute.org/sites/default/files/documents/cervical-cancer-in-indiachallenges-and-opportunities.pdf (Accessed on 19th May 2021)

39. Vaccarella, S., Lortet-Tieulent, J., Plummer, M., Franceschi, S., \& Bray, F. (2013). Worldwide trends in cervical cancer incidence: impact of screening against changes in disease risk factors. European journal of cancer, 49(15), 3262-3273.

\section{Figures}


Incidence of cervical cancer over three decades (1990-2019)
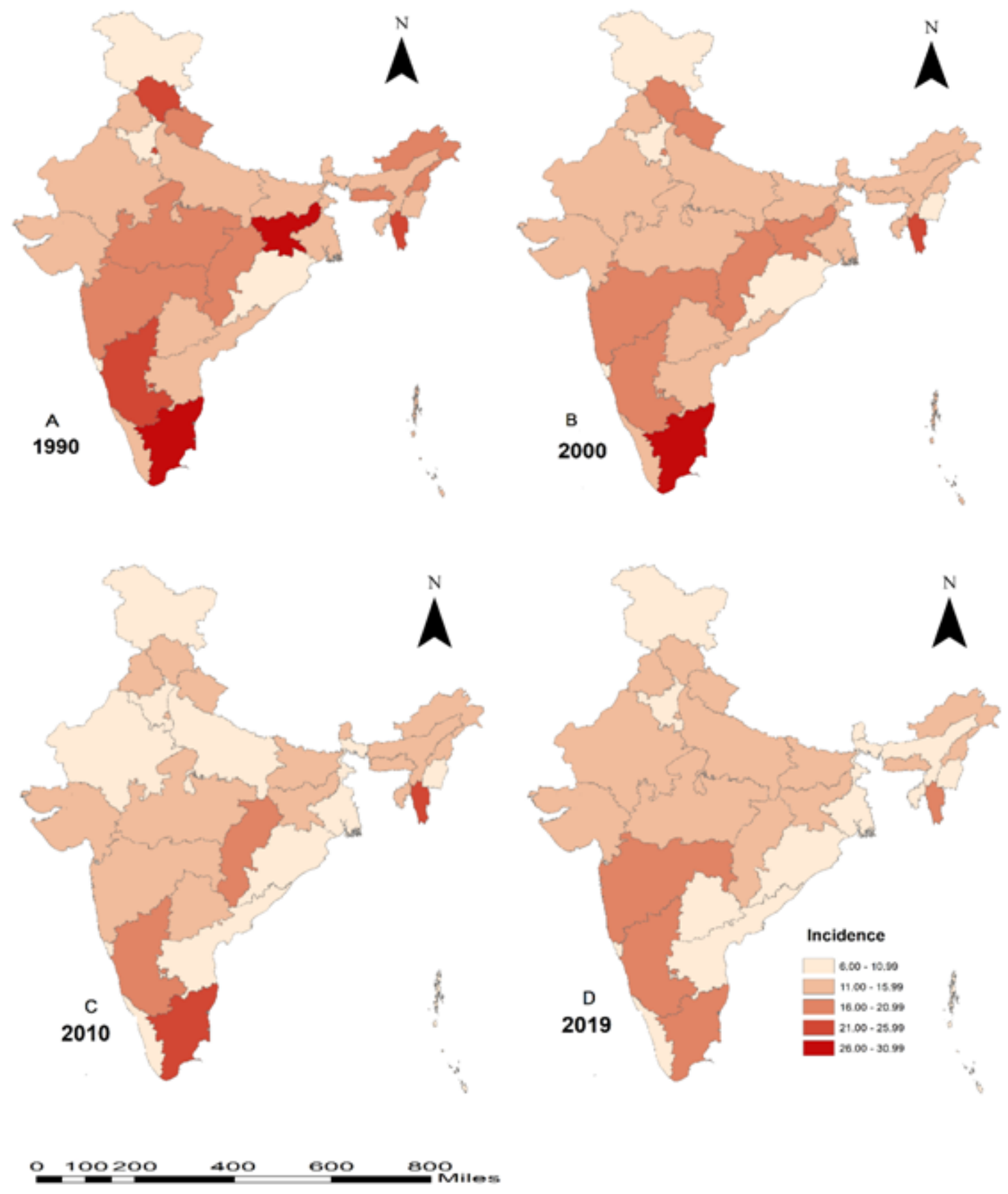

\section{Figure 1}

Incidence of cervical cancer from 1990 to 2019 per 100,000 women in India A- Incidence of cervical cancer per 100,000 women in 1990, B- Incidence of cervical cancer per 100,000 women in 2000, CIncidence of cervical cancer per 100,000 women in 2010, D- Incidence of cervical cancer per 100,000 women in 2019, 
Mortality of cervical cancer over three decades (1990-2019)
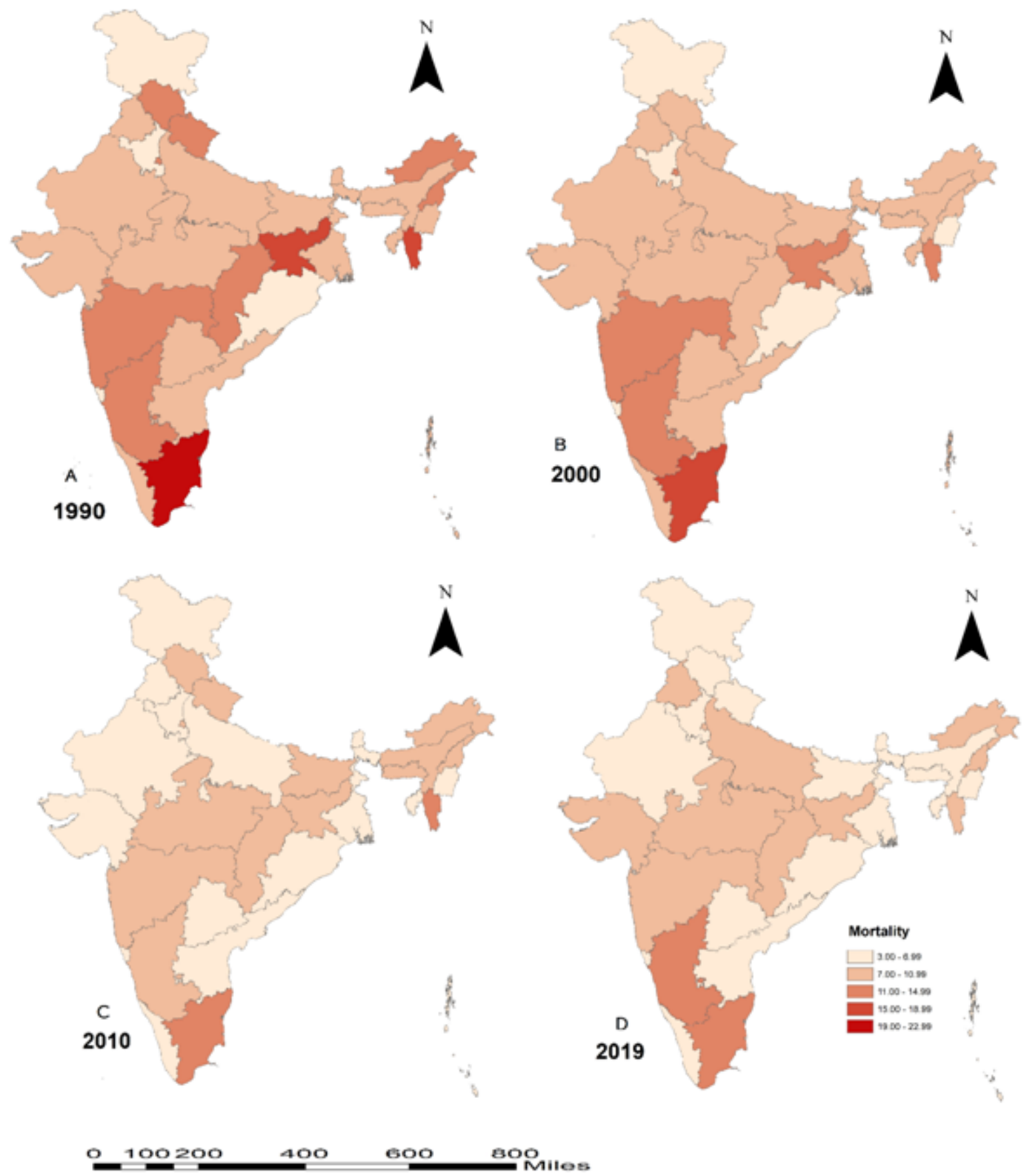

\section{Figure 2}

Mortality of cervical cancer from 1990 to 2019 per 100,000 women in India A- Mortality of cervical cancer per 100,000 women in 1990 , B- Mortality of cervical cancer per 100,000 women in 2000, C- Mortality of cervical cancer per 100,000 women in 2010, D- Mortality of cervical cancer per 100,000 women in 2019 
Female CervicalCancer Inc ide uce Per 100,000 for all Ages by States

\begin{tabular}{|c|c|c|c|c|c|c|c|}
\hline \multirow{2}{*}{ Ranl 1900} & \multirow{2}{*}{ Lecation } & \multirow{2}{*}{ Incidence [C]] } & \multirow{2}{*}{\multicolumn{2}{|c|}{ Rank 2019}} & \multirow{3}{*}{ Lecation } & \multirow{2}{*}{ Incidence $[\mathrm{CT}]$} & \multirow{2}{*}{ Percentage Change } \\
\hline & & & & & & & \\
\hline 1 & Tamil Nadu & $30.92[15.7841 .77]$ & & 1 & & $19.91\left\{\begin{array}{lll}11.27 & 26.83\end{array}\right]$ & -35.61 \\
\hline 2 & Jharkhand & $26.47[15.86 \quad 37.45]$ & & 2 & Karnataka & $19.83\left[\begin{array}{lll}11.86 & 27.51]\end{array}\right.$ & -8.24 \\
\hline 3 & Mizoram & $23.87[13.1534 .6]$ & & 3 & Mizoram & $18.99[9.529 .21]$ & -20.44 \\
\hline 4 & Himachal Pradesh & $22.57[13.0931 .2]$ & & 4 & Maharashtra & $16.75\left[\begin{array}{lll}11.08 & 22.65\end{array}\right]$ & -12.85 \\
\hline 5 & Delhi & $21.83\left[\begin{array}{lll}12.79 & 28.82\end{array}\right.$ & & 5 & Chhattiggarh & $14.81[10.3620 .3]$ & -21.76 \\
\hline 6 & Karnataka & $21.61[12.1928 .87]$ & & 6 & Arunachal Pradesh & 14.01 [9.2 20.68] & -25.95 \\
\hline 7 & Maharashtra & $19.22\left[\begin{array}{lll}11.95 & 25.08\end{array}\right]$ & & 7 & Uttar Pradesh & $13.48[9.2121 .21]$ & -7.86 \\
\hline 8 & Chhattisgarh & $18.93\left[\begin{array}{lll}12.4 & 27.93]\end{array}\right.$ & & 8 & Madhya Pradesh & $13.41[9.7717 .92]$ & -18.38 \\
\hline 9 & Ar unachal Pradesh & $18.92\left[\begin{array}{lll}12.15 & 26.12\end{array}\right]$ & & 9 & Gujarat & $13.26[9.31$ 18.8] & -15.16 \\
\hline 10 & Nagaland & $18.4[11.926 .12]$ & & 10 & Jharkhand & $13.18[9.8418 .37]$ & -50.21 \\
\hline 11 & Uttarakhand & $17.67\left[\begin{array}{lll}11.76 & 28.4]\end{array}\right.$ & & 11 & India & 13.1 [10.18 17.09] & -21.32 \\
\hline 12 & India & 16.65 [13.2 21.45] & & 12 & Punjab & $13[9.6517 .82]$ & -11.92 \\
\hline 13 & Madihya Pradesh & $16.43\left[\begin{array}{lll}11.48 & 23.09\end{array}\right]$ & & 13 & Nagaland & $12.95[7.5919 .42]$ & -29.62 \\
\hline 14 & Meghalaya & $16.03\left[\begin{array}{ll}10.53 & 24.22\end{array}\right]$ & & 14 & Uttar akhand & 12.32 [8.8 19.28] & -30.28 \\
\hline 15 & Gujarat & $15.63[11.6820 .97]$ & & 15 & Delhi & 11.87 [8.5 15.78] & -45.63 \\
\hline 16 & Tripura & $15.44\left[\begin{array}{lll}10.03 & 22.54]\end{array}\right.$ & & 16 & Rajasthan & $11.77\left[\begin{array}{lll}8.32 & 17.92]\end{array}\right.$ & 0.43 \\
\hline 17 & Punjab & $14.76[10.75$ 19.8] & & 17 & Himachal Pradesh & $11.66[8.0516 .25]$ & -48.34 \\
\hline 18 & Telangana & $14.75[9.2324 .03]$ & & 18 & Bithar & $11.46[7.7918 .89]$ & -13.7 \\
\hline 19 & Uttar Pradesh & $14.63[9.7125 .81]$ & & 19 & Meghalaya & $11.4[7.5916 .99]$ & -28.88 \\
\hline 20 & Other Union Territories & 14.51 (9.65 20.06) & & 20 & Assam & $10.68[7.4919 .26]$ & -17.21 \\
\hline 21 & Skkim & $14.23[9.6121 .41]$ & & 21 & Tripura & $10.64\left[\begin{array}{lll}7 & 15.99\end{array}\right]$ & -31.09 \\
\hline 22 & Andhra Pradest' & $14.17\left[\begin{array}{l}9 \\
22.33\end{array}\right]$ & & 22 & Andhra Pradesh & $9.81[6.3416 .96]$ & -30.77 \\
\hline 23 & West Bengal & $13.64[9.519 .34]$ & & 23 & Tebrigans & $9.76[6.0316 .26]$ & -33.83 \\
\hline 24 & Bithar & $13.28(8.57 \quad 23.26)$ & & 24 & Sikkim & $9.72[6.6114 .78]$ & -31.69 \\
\hline 25 & Assam & $12.9[3.6228 .1\}$ & & 25 & West Bengal & $9.67\left[\begin{array}{lll}7.06 & 13.94\end{array}\right]$ & -29.11 \\
\hline 26 & Kerab & $12.76\left[\begin{array}{lll}9.1 & 16.5\end{array}\right]$ & & 26 & Other Union Territories & $9.5\left[\begin{array}{lll}6.34 & 14.04]\end{array}\right.$ & -34.53 \\
\hline 27 & Manipur & $11.77[7.8619 .09$ ] & & 27 & Kerala & $9.35[6.5712 .921$ & -26.72 \\
\hline 28 & Rajasthan & 11.72 [8.17 18.85$]$ & & 28 & Manipur & $9.25[5.914 .93]$ & -21.41 \\
\hline 29 & Odisha & $10.34|6.2926 .48|$ & & 29 & Haryana & $7.85\left[\begin{array}{lll}5.2 & 15.03\end{array}\right]$ & -16.49 \\
\hline 30 & Goa & $10.17|5.1916 .28|$ & & 30 & Odisha & $7.1\left[\begin{array}{lll}4.42 & 17.34\end{array}\right]$ & -31.33 \\
\hline 31 & Haryana & $9.4\left[\begin{array}{lll}6.17 & 19.04\end{array}\right]$ & & 31 & Goa & $7.02[4.5511 .46]$ & -30.97 \\
\hline 32 & Jammu \& Kashmir and Lad & $7.24[4.48 \quad 18.14]$ & & 32 & Jammu \& Kashmir and Ladakh & $6.13[3.9515 .71]$ & -15.33 \\
\hline & Western Region & & North-East. Region & & Central Region & & Inda \\
\hline & Souther n Region & & Eastern Region & & Nor thern Region & & \\
\hline & All Union Territories & $\longrightarrow$ & Decreasing / Steady Rank & --1 & Increasing Rank & & \\
\hline
\end{tabular}

\section{Figure 3}

Ranks of Age-Standarized cervical cancer incidence rate per 100,000 women population for all ages in 1990 and 2019 in India. 


\begin{tabular}{|c|c|c|c|c|c|c|c|}
\hline \multirow[b]{2}{*}{ Rank 1990} & \multirow[b]{2}{*}{ Iocation } & \multicolumn{4}{|c|}{ Female CerricalCancer Mortality Per 100,000 fr all.Ages by States } & \multirow[b]{2}{*}{ Incidence [CI] } & \multirow[b]{2}{*}{ Percentinge Change } \\
\hline & & Incidence [CT] & & Rank 2019 & Location & & \\
\hline 1 & Tamil Nadu & $20.73[10.8827 .6]$ & & 1 & Tarnil Nadu & $11.57[6.31 \quad 15.59]$ & -44.19 \\
\hline 2 & Jhar khand & $17.95[11.3425 .02]$ & & 2 & Karnataka & $11.14\left[\begin{array}{ll}0.67 & 15.1]\end{array}\right.$ & -18.98 \\
\hline 3 & Mizoram & $15.03[8.6420 .55]$ & & 3 & Mizoram & $10.9\left[\begin{array}{lll}5.64 & 16.15\end{array}\right]$ & -27.48 \\
\hline 4 & Delhi & $14.6[8.7819 .1]$ & & 4 & Maharashtra & $9.26[6.2212 .29]$ & -26.74 \\
\hline 5 & Himachal Pradesh & 13.92 |8.73 18.8| & & 5 & Chthattisgarth & $8.71\left[\begin{array}{lll}6.3 & 12.97]\end{array}\right]$ & -27.23 \\
\hline 6 & Karnataka & $13.75 \mid 7.8318 .03\}$ & & 6 & Arunachal Pradesh & $7.99[5.5210 .95]$ & -35.15 \\
\hline 7 & Maharashtra & $12.64[7.9416 .16]$ & & 7 & Madhya Pradesh & $7.88[5.85 \quad 10.47]$ & -27.44 \\
\hline 8 & Arunachal Pradesh & $12.32[8.04 \quad 17.19]$ & & 8 & Jharkhand & $7.87[5.8410 .94]$ & -56.16 \\
\hline 9 & Ohthattisgarh & $11.97[7.9516 .98]$ & & 9 & Uttar Pradesh & $7.79|5.4313 .89|$ & -19.61 \\
\hline 10 & Nagaland & $11.83[8.0916 .02]$ & & 10 & Nagaland & $7.57[4.81$ 10.93] & -36.01 \\
\hline 11 & Uttarakhand & $11.23\left[\begin{array}{lll}7.58 & 17.61]\end{array}\right.$ & & 11 & India & $7.38 \mid 5.71$ 10.13] & -32.29 \\
\hline 12 & India & $10.9\left[\begin{array}{lll}8.59 & 13.74\end{array}\right]$ & & 12 & Punjab & $7.14[5.19 .72]$ & -23.55 \\
\hline 13 & Madhya Pradesh & $10.86\left[\begin{array}{lll}7.46 & 15.51\end{array}\right]$ & & 13 & Gujarat & $7.12[5.0410 .56]$ & -31.07 \\
\hline 14 & Meghalaya & $10.47\left[\begin{array}{lll}7.01 & 15.53\end{array}\right]$ & & 14 & Delhi & $7.11[4.819 .26]$ & -51.3 \\
\hline 15 & Gujar at & $10.33\left[\begin{array}{lll}7.79 & 13.44\end{array}\right]$ & & 15 & Meghalaya & $6.84[4.869 .84]$ & -34.67 \\
\hline 16 & Tripura & $10.02\left[\begin{array}{lll}6.71 & 14.37]\end{array}\right]$ & & 16 & Uttarakhand & $6.83[4.9411 .45]$ & -39.18 \\
\hline 17 & Uttar Pradesh & $9.69[6.2418 .03]$ & & 17 & Bhar & $6.55\left[\begin{array}{lll}4.49 & 11.13]\end{array}\right.$ & -24.71 \\
\hline 18 & Punjab & $9.34\left[\begin{array}{lll}6.95 & 12.54\end{array}\right]$ & & 18 & Himachal Pradesh & $6.49[4.78 .81 \mid$ & -53.38 \\
\hline 19 & Telangana & $9.21 \mid 5.615 .5\}$ & & 19 & Assam & $6.39[4.6312 .52]$ & -25.96 \\
\hline 20 & Sikkim & $9.19\left[\begin{array}{ll}6.28 & 13.53\end{array}\right]$ & & 20 & Rajasthan & $6.26[4.25 \quad 10.45]$ & -17.41 \\
\hline 21 & West Bergal & $9.03\left[\begin{array}{lll}6.32 & 12.15\end{array}\right]$ & & 21 & Tripura & $6.25[4.369 .15]$ & -37.62 \\
\hline 22 & Andhra Pr adest' & $8.97[5.6414 .29]$ & & 22 & Manipur & $5.59[3.788 .86]$ & -27.59 \\
\hline 23 & Other Union Territories & $8.79\left[\begin{array}{lll}6.06 & 11.97]\end{array}\right]$ & & 23 & Sikkim & $5.47[3.97 .88]$ & -40.48 \\
\hline 24 & Bhar & $8.7[5.65 \quad 15.76]$ & & 24 & Andinra Prades'ı & $5.34[3.59 .671$ & -40.47 \\
\hline 25 & Assam & $8.63\left[\begin{array}{lll}5.68 & 18.13]\end{array}\right.$ & & 25 & West Bengal & $5.24[3.897 .89]$ & -41.97 \\
\hline 26 & Kerala & $8.23[5.77 \quad 10.63]$ & & 26 & Other Union Territories & $5.14\left[\begin{array}{lll}3.56 & 7.72\end{array}\right]$ & -41.52 \\
\hline 27 & Manipur & $7.72\left[\begin{array}{lll}5.5 & 12.4\end{array}\right]$ & & 27 & Telangana & $5.07[3.239 .03]$ & -44.95 \\
\hline 28 & Rajasthan & $7.58[5.24 \quad 12.67]$ & & 28 & Kerala & $4.77[3.296 .49]$ & -42.04 \\
\hline 29 & Odsha & $6.86\left[\begin{array}{lll}4.04 & 17.54\end{array}\right]$ & & 29 & Haryana & $4.32[2.859 .54]$ & -26.53 \\
\hline 30 & Goa & $6.24\left[\begin{array}{lll}3.74 & 10.19\end{array}\right]$ & & 30 & Odsha & $4.22[2.6410 .63]$ & -38.48 \\
\hline 31 & Haryana & $5.88\left[\begin{array}{lll}3.79 & 12.14\end{array}\right]$ & & 31 & Goa & $3.58[2.356 .27]$ & -42.63 \\
\hline 32 & Jammu \& Kashmi and Ladakh & $4.6[2.8512 .09]$ & & 32 & Jammu \& Kashmir and Ladakh & $3.39[2.218 .78]$ & -26.3 \\
\hline & Western Region & & North-East Region & & Central Region & & India \\
\hline & Southern Region & & Eastern Region & & Northern Region & & \\
\hline & AllUnion Territories & $=$ & Decreasing / Steady Rank. & -0 & Increasing Rank & & \\
\hline
\end{tabular}

\section{Figure 4}

Ranks of age-standarized cervical cancer mortality rate per 100,000 women population for all ages in 1990 and 2019 in India. 

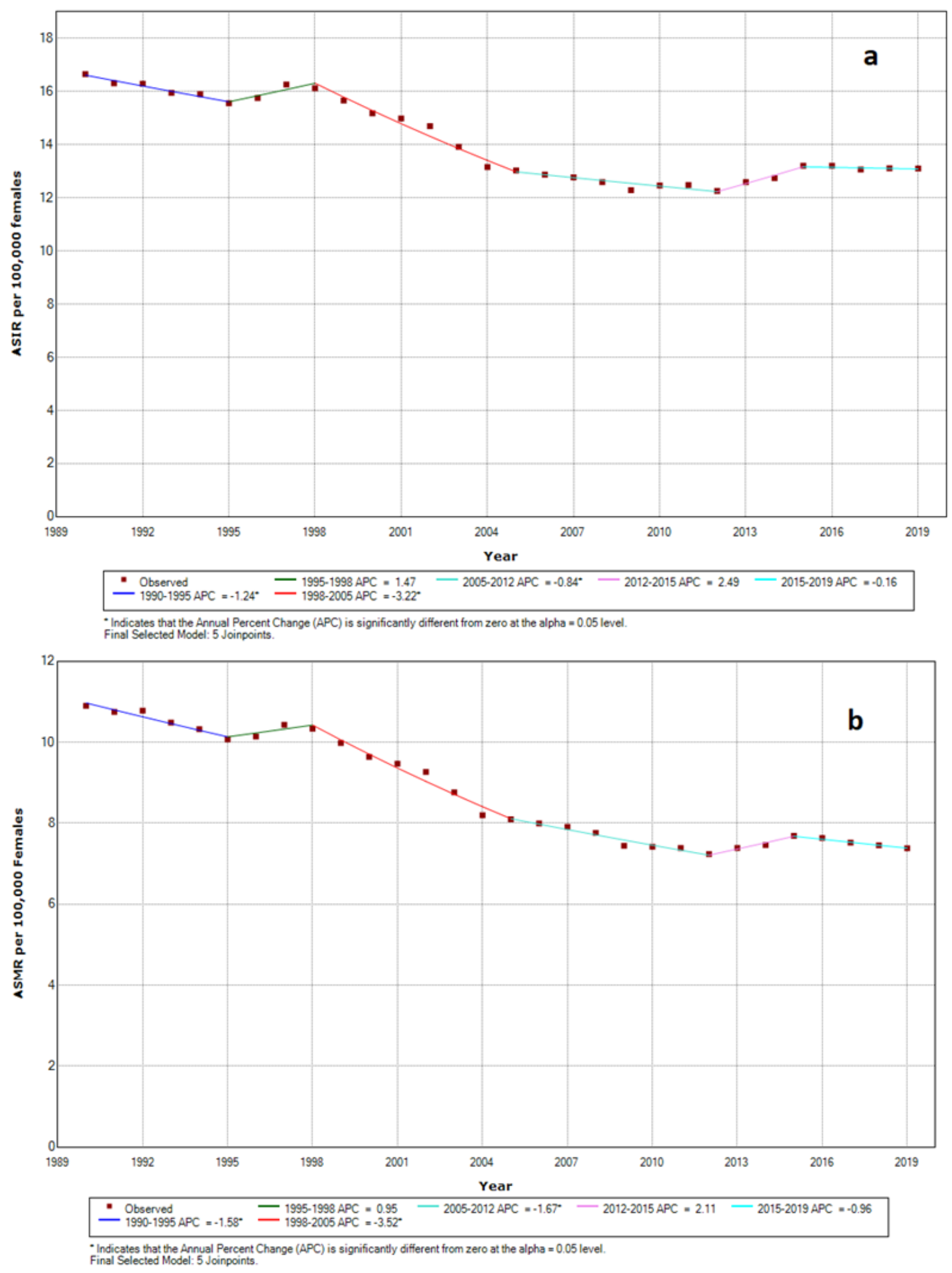

Figure 5

Trends in Age-Standardized Cervical Cancer a) Incidence and b) Death Rates Using JoinpointRegression Analysis across India

\section{Supplementary Files}


This is a list of supplementary files associated with this preprint. Click to download.

- Supplementaryfile.docx 